\title{
Racial disparities in social media use, sexual risk behaviors, and HIV/AIDS stigma among men who have sex with men
}

\author{
Renee Garett ${ }^{1}$, Evan A. Krueger ${ }^{2}$, Sean D. Young ${ }^{3}$ \\ ${ }^{1}$ ElevateU, Los Angeles, California, USA \\ ${ }^{2}$ Department of Community Health Sciences, University of California, Los Angeles (UCLA), California, USA \\ ${ }^{3}$ Department of Family Medicine, University of California, Los Angeles (UCLA), Los Angeles, California, USA
}

\begin{abstract}
Introduction: Social media is increasingly being used as a tool for communication and has been associated with sexual risk. Men who have sex with men (MSM) and racial/ethnic minorities are at an increased risk for contracting human immunodeficiency virus (HIV) and acquired immune deficiency syndrome (AIDS). Racial/ethnic minorities also use social media at a higher rate than Whites. MSM may use social media to discuss health-related matters or to find sexual partners. The aim of this study was to identify how racial and ethnic MSM minority use social media throughout the course of a twelveweek study. We also sought to explore how variations in social media between these populations might impact sexual risk behavior, such as number of sexual partners.
\end{abstract}

Material and methods: Data from a Facebook-based HIV intervention in 2011 and 2012 were evaluated to determine the impact of race and ethnicity on social media use, sexual risk behaviors, and HIV/AIDS stigma.

Results: Compared with Latinos, African-Americans were less likely to discuss sexual partners, having sex with men, or condom use on social media. Compared with Latinos, Whites and Asians met a greater number of sexual partners using social media and reported higher HIV/AIDS stigma.

Conclusions: Future behavioral interventions must account for racial and ethnic differences in social media use and sexual risk behaviors among MSM. Intervention development suggestions are discussed.

HIV AIDS Rev 2018; 17, 3: 176-180 DOI: https://doi.org/10.5114/hivar.2018.78489

Key words: men who have sex with men, social media, HIV/AIDS, online social networks.

\section{Introduction}

The human immunodeficiency virus (HIV) and acquired immune deficiency syndrome (AIDS) pandemic remains concentrated with key populations, such as men who have sex with men (MSM). This pattern holds true in Los Angeles, California, where MSM represented an estimated $82 \%$ of HIV diagnoses in 2010 [1]. Racial/ethnic minorities have accounted for the bulk of new infections in California, with the highest percentage of new diagnoses occurring amongst Latinos (45\%), compared to Whites (25\%), and African Americans (24\%). African Americans represented the highest rate of new diagnoses (52 per 100,000), compared to Latinos (19 per 100,000), and Whites (16 per 100,000) [1].
Address for correspondence: Dr. Sean D. Young, Department of Family Medicine, University of California, Los Angeles (UCLA), 10880 Wilshire Blvd., Ste. 1800, 90024 Los Angeles, California, USA, e-mail: sdyoung@mednet.ucla.edu
Article history:

Received: 10.08.2017

Received in revised form: 06.10.2017

Accepted: 02.03.2018

Available online: 15.08 .2018
International Journal of HIV-Related Problems

HIV \& AIDS

R e vi e w 
Online social networking websites are widely used platforms for communication. Among Internet users, racial/ ethnic minorities regularly access these platforms at higher rates than Whites $[2,3]$. Gay, lesbian, and bisexual individuals are also more likely to use such platforms than heterosexual individuals, with recent reports showing that $80 \%$ of gay/lesbian adults use a social networking site as compared to $58 \%$ of the U.S. general public $[4,5]$. Surveys indicate that different racial/ethnic populations display varying trends in Internet and social media use over time. For example, the "digital divide" between African Americans and Whites is gradually diminishing (i.e., the percentage of African American Internet users increased from 67\% in 2009 to $80 \%$ in 2013) [6]. Moreover, between 2010 and 2013, the use of social networking websites increased across all races, with English-speaking Latino and African American Internet users accessing social media platforms at higher rates than White users. Since 2013, the use of social networking websites by English-speaking Latinos has been statistically significantly higher than that of other races [7-9]. Differences also exist with regard to preferences for social media platforms. Although Facebook remains the most popular platform, young African Americans are twice as likely to use Twitter, and Latinos are more likely to engage in instant messaging in comparison to Whites $[9,10]$.

Prior studies have demonstrated that African American and Latino MSM use online social networks to find sexual partners [11], thus different patterns in social media use between groups might differentially impact sexual risk behavior. To our knowledge, however, there has not been a longitudinal analysis that examines the association between racial/ethnic differences in social media use, and HIV-related attitudes and behaviors. Therefore, this study aims to understand the longitudinal impact of race and ethnicity on online social network use and sexual risk behavior. Given the rapid change in social media use by different ethnic groups over a short period of time, this study adds to the literature by exploring if sexual risk behaviors also change as rapidly. Data for this article were culled from the Harnessing Online Peer Education (HOPE) study, an online peer-led HIV prevention intervention that was conducted through an online social networking website (Facebook).

\section{Material and methods}

\section{Intervention}

The HOPE study was conducted as a 12-week, twoarm, randomized controlled trial to study the effectiveness of an HIV peer education program delivered via Facebook. Online community groups permitted for a degree of anonymity, which made it more likely that people experiencing stigma from HIV/AIDS and other sources would join and contribute to the groups. Participants in the control group received only general health information, while participants in the intervention group received health information and peer-led counseling. Several measures tracked throughout the length of the study showed how the program engaged participants in HIV-related discussions and facilitated HIV prevention behavior change. The HOPE study was approved by the UCLA Institutional Review Board (IRB), and the study design adheres to current recommendations for conducting research using social networking technology [12].

Between September 2010 and February 2011, 122 subjects were recruited for the study. After excluding 4 duplicate respondents and 6 participants who only completed the initial survey items of the 92-question survey, 112 participants were included in the final study. Participants were recruited both online and offline (e.g., gay venues in Los Angeles, such as bars, schools, gyms, and community organizations). The study used banner ads and posts on MySpace, Facebook, and Craigslist to recruit participants online. Eligible participants were: 1) male, 2) 18 years of age or older, 3) current Facebook users, 4) Los Angeles residents, and 5) individuals who had sex with a man in the past year. The study was primarily designed for African American and Latino MSM. In accord with this intention, 70\% of the final sample was from African American and Latino MSM communities. The study was then broadened to include MSM of other races/ethnicities to diversify the social networking groups. Although HIV status was not an inclusion criterion, it was expected that most participants would be HIV-negative; in fact, $100 \%$ of participants were HIV-negative. Upon completing the eligibility survey, Facebook Connect was used to verify that eligible individuals were uniquely registered Facebook users to reduce duplicate respondents. Participants were then provided with study information and consent forms, and were asked to complete a baseline survey.

\section{Assessment and measures}

Participants were assessed at baseline, post-intervention, and one year following completion of the study; participants received $\$ 30, \$ 40$, and $\$ 50$ (US) for completing the surveys, respectively. This monetary compensation is in line with other HIV/AIDS studies and was approved by the IRB. The study itself was conducted between March and June 2011, with the one-year follow-up assessment occurring in June 2012. At the one-year follow-up assessment, there was an $83 \%$ overall retention rate (93 total respondents).

\section{Demographics}

Demographic questions focused on race/ethnicity, sexual orientation, age, work status, and relationship status. The question regarding ethnicity included boxes that the participant could tick to indicate their race. Like the demographic questions on the 92-page baseline questionnaire, the participants self-reported their answers.

\section{Online social network use}

Participants were asked to consider the previous 3 months, and indicate the frequency of discussion about and comfort with the following topics: 1) sexual partners, 2) sexual posi- 
tions, 3) sexual health, 4) using condoms during sex, 5) using drugs or alcohol during sex, 6) getting an HIV/STI test, 7) HIV/STI status, 8) other sexual partners, 9) having sex with men, and 10) having sex with women. In addition, participants were asked to rate the importance and ease of using social networks to meet sexual partners, in comparison to face-to-face/ in-person meetings. Participants were asked these questions at baseline, a 12-week post-intervention assessment, and a 15-month follow-up assessment.

\section{HIV / AIDS stigma}

A 15-item questionnaire was designed to broadly measure HIV/AIDS stigma. This questionnaire was adapted from previous HIV/AIDS stigma questionnaires [12, 14], and was designed to record each participant's views of HIV/ AIDS and people living with HIV/AIDS (PLWHA). Each question was answered using a 5-point Likert scale, with responses ranging from "strongly disagree" to "strongly agree". Example questions include: "Nurses with HIV should not be allowed to work in hospitals", and "People with HIV are likely to use illegal drugs". Four items were reverse coded for the analysis.

\section{Sexual risk behavior}

Participants were asked to indicate how many alcoholic drinks they had daily or weekly in the past three months. To assess sexual risk, participants were asked if they had had sex under the influence of an illicit substance or alcohol. Participants also provided the number of times they engaged in the following during the past three months: 1) condomless vaginal sex, 2) condomless receptive anal sex, 3) condomless insertive anal sex, or 4) oral sex. The survey explicitly asked the participants if they had engaged in sex "with a condom" and "without a condom" to ensure that there was no confusion over the wording of "protected/ unprotected".

\section{Analysis}

All analyses were conducted using STATA 13 (StataCorp LP, College Station, TX, USA). Given the small number of White $(n=12)$ and Asian $(n=2)$ participants, we combined them into a single $(n=14)$ category named 'White/ Asian'. Repeated measures mixed model analysis was used to evaluate the association between race and sexual risk, online social network use, and HIV/AIDS stigma. The models were adjusted for age, work status, sexual orientation, assessment time point, and intervention group (intervention vs. control).

\section{Results}

\section{Demographics}

The mean age of the participants was 32.11 years. The majority of participants self-identified as gay (78.7\%), Latino
Table 1. Basic demographics of participants at baseline $(n=112)$

\begin{tabular}{|c|c|c|}
\hline Factor & $n$ & $\%$ \\
\hline \multicolumn{3}{|l|}{ Group } \\
\hline Intervention & 57 & 50.9 \\
\hline Control & 55 & 49.1 \\
\hline \multicolumn{3}{|l|}{ Age } \\
\hline Mean (SD) & 32.1 & 10.1 \\
\hline \multicolumn{3}{|l|}{ Sexual orientation } \\
\hline Gay & 85 & 78.7 \\
\hline Bisexual & 21 & 19.4 \\
\hline Others & 2 & 1.9 \\
\hline \multicolumn{3}{|l|}{ Race } \\
\hline Latino & 67 & 59.8 \\
\hline African American & 31 & 27.7 \\
\hline White/Asian & 14 & 12.5 \\
\hline \multicolumn{3}{|l|}{ Work situation } \\
\hline Full time & 40 & 36.4 \\
\hline Part time & 25 & 22.7 \\
\hline Students & 20 & 18.2 \\
\hline Unemployed & 25 & 22.7 \\
\hline \multicolumn{3}{|l|}{ Relationship status } \\
\hline Single & 92 & 82.9 \\
\hline Married & 13 & 11.7 \\
\hline Others $^{*}$ & 6 & 5.4 \\
\hline
\end{tabular}

"Separated, divorced, widowed, or other

(59.8\%), and single (82.9\%). More than half of the participants did not work full time (63.6\%) (Table 1).

\section{Race and online social network use}

Participants who were White/Asian reported meeting significantly more sexual partners through online social networks than Latino participants $(p=0.001)$. In comparison to Latinos, African Americans were less likely to talk to others about sexual partners $(p=0.029)$, having sex with men $(p=0.036)$, and using condoms during sex $(p=0.014)$. Participants' comfort levels did not differ in regard to talking to others about all topics of sexuality and sexual health using online social networks.

\section{Race and HIV/AIDS stigma}

White/Asian participants expressed significantly higher levels of HIV/AIDS-related stigma than Latino participants $(p=0.005)$.

\section{Race and sexual risk behavior}

On average, African Americans had fewer alcoholic drinks per day, and were less likely to engage in condomless 
Table 2. Coefficients and confidence intervals from adjusted mixed model for online social network use and sexual risk behavior by race

\begin{tabular}{|c|c|c|c|c|}
\hline \multirow{2}{*}{ Question } & \multirow{2}{*}{ Race } & \multirow{2}{*}{ Beta } & \multicolumn{2}{|c|}{ 95\% Confidence interval } \\
\hline & & & Upper & Lower \\
\hline \multirow[t]{2}{*}{ How many sexual partners have you met on the Internet? } & African American & 0.017 & -0.63 & 0.66 \\
\hline & White/Asian $^{\dagger}$ & 0.62 & 0.25 & 0.99 \\
\hline \multirow[t]{2}{*}{ On average, how many alcoholic drinks do you have each day? } & African American $^{*}$ & -0.94 & -1.66 & -0.23 \\
\hline & White/Asian & -0.14 & -0.8 & 0.51 \\
\hline \multirow{2}{*}{$\begin{array}{l}\text { How many times have you talked to others about sexual } \\
\text { partners on online social networks? }\end{array}$} & African American ${ }^{*}$ & -0.48 & -0.91 & -0.050 \\
\hline & White/Asian & 0.011 & -0.52 & 0.54 \\
\hline \multirow{2}{*}{$\begin{array}{l}\text { How many times have you talked to others about using } \\
\text { condoms during sex on online social networks? }\end{array}$} & African American ${ }^{*}$ & -0.58 & -1.05 & -0.12 \\
\hline & White/Asian & -0.40 & -0.98 & 0.17 \\
\hline \multirow{2}{*}{$\begin{array}{l}\text { How many times have you talked to others about having sex } \\
\text { with men on online social networks? }\end{array}$} & African American ${ }^{*}$ & -0.50 & -0.96 & -0.031 \\
\hline & White/Asian & -0.26 & -0.84 & 0.32 \\
\hline \multirow[t]{2}{*}{ HIV/AIDS stigma composite } & African American & 0.22 & -1.79 & 2.23 \\
\hline & White/Asian $^{\dagger}$ & 3.07 & 0.9 & 5.24 \\
\hline \multirow{2}{*}{$\begin{array}{l}\text { How many times have you had condomless receptive anal } \\
\text { intercourse? }\end{array}$} & African American $^{\dagger}$ & -0.43 & -0.69 & -0.16 \\
\hline & White/Asian & -0.13 & -0.45 & 0.19 \\
\hline
\end{tabular}

All models were adjusted for age, work situation, sexual orientation, assessment time point, and intervention group. Latinos were used as the reference group. $p<0.05 ;{ }^{*} p<0.01$

receptive anal intercourse in comparison to Latinos $(p=0.01$ and $p=0.002$, respectively) (Table 2 ).

\section{Discussion}

This study analyzed the longitudinal impact of race on social media use, sexual risk behavior, and HIV/AIDS stigma among a sample of predominately African American and Latino MSM in a Facebook HIV intervention trial. Compared with Latinos, African American participants reported lower levels of sexual risk with respect to condomless receptive anal sex and daily alcohol consumption. Previous analyses showed similar results after a 12-week follow-up assessment [15], and the current analysis indicates prevention effects may persist for up to one year. This finding, although a conclusion limited in strength due to the small sample size, enhances our understanding of the role that race plays in shaping behavioral outcomes over time. Moreover, our results suggest that African American MSM were less likely to use online social networks to discuss sexual health (i.e., using condoms during sex) and same-sex sexual behavior (i.e., having sex with men and sexual partners). Thus, it will be vital for future interventions to develop culturally appropriate means to facilitate sensitive discussions among MSM minority. This will be of particular importance in light of the fact that offline prevention efforts have been difficult due to high levels of social stigma associated with being MSM in the African American community [16, 17].

White/Asian participants reported higher levels of HIV/ AIDS stigma and met more sexual partners using online social networks than Latino participants. Previous studies have suggested that individuals may use online social networks to meet sexual partners to avoid potential HIV/AIDS stigma $[11,18]$. As shown in previous work [14], the stigma associated with acts that suggest a person has HIV/AIDS (e.g., getting tested for HIV/AIDS) may influence people to avoid getting tested for HIV. In this analysis, we showed that stigma was higher in the African American and Latino communities. Although the finding here is consistent (i.e., higher HIV/AIDS stigma is associated with higher likelihood of seeking sexual partners online), it was surprising because the White community is generally associated with a lower level of HIV/AIDS-related stigma [16, 19, 20].

\section{Conclusions}

This study has a number of limitations. First, the sample size was small and therefore might lack the necessary power to have discovered additional differences from preliminary analyses. Larger studies involving more participants will be needed to confirm the findings and explore additional differences in social media use as a result of race or ethnicity. Second, our online recruitment methods were not verified. Future studies should attempt to verify the effectiveness of banner ads and other electronic means of recruiting potential participants. Third, the participants' HIV status was not known until the baseline survey was completed. Thus, future studies should implement more expansive screening procedures to determine HIV status. Finally, HIV/AIDS stigma is a multifaceted construct, and the scale we used might not have captured intersections between stigmas experienced by MSM of color. For example, stigma from 
racism and homophobia are relevant to MSM of color and might explain the difference in measured HIV/AIDS stigma between the White/Asian and Latino participants. Future studies should take these racial and ethnic differences into consideration when tailoring intervention messages to the needs of the targeted communities.

\section{Conflict of interest}

The authors declare no potential conflicts of interest with respect to the research, authorship, and/or publication of this article.

\section{References}

1. California Department of Health. Annual HIV surveillance report. 2012. Available at: http://publichealth.lacounty.gov/wwwfiles/ph/ hae/hiv/2012AnnualHIVSurveillanceReport.pdf (Accessed: 14 April 2016).

2. Pew Research Center. Spring change assessment 2010. Available at: http://www.pewinternet.org/Shared-Content/Data-Sets/2010/May2010--Cellophones.aspx (Accessed 1 June 2016).

3. Smith A. Technology trends among people of color. Pew Research Center. 2010. Available at: http://www.pewinternet.org/2010/09/ 17/technology-trends-among-people-of-color/ (Accessed: 1 June 2016).

4. Harris Interactive. Gays, lesbians and bisexuals lead in usage of online social networks. Available at: http://www.witeckcombs.com/news/ releases/20070102_socialnetworks.pdf (Accessed: 15 June 2016).

5. Pew Research Center. Social networking fact sheet. Available at: http://www.pewinternet.org/fact-sheets/social-networking-fact-sheet/ (Accessed: 12 June 2016).

6. Horrigan J. Access for African Americans. 2009. Available at: http:// www.pewinternet.org/2009/07/22/access-for-african-americans/ (Accessed: 12 June 2016).

7. Pew Research Center. A survey of LGBT Americans: Attitudes, experiences, and values in changing times. 2013. Available at: http://www.pewsocialtrends.org/files/2013/06/SDT_LGBT-Americans_06-2013.pdf (Accessed: 12 June 2016).

8. Smith A. Who's on what: Social media trends among communities of color. 2011. Available at: http://www.pewinternet. org/2011/01/25/whos-on-what-social-media-trends-among-communities-of-color/ (Accessed: 12 June 2016).

9. Duggan M, Brenner J. The demographics of social media users, 2012. 2013. Available at: http://www.pewinternet.org/fact-sheets/ social-networking-fact-sheet/ (Accessed: 12 June 2016).

10. Livingston G. Latinos and digital technology, 2010. 2011. Available at: http://www.pewhispanic.org/2011/02/09/latinos-and-digital-technology-2010/ (Accessed: 11 June 2016).

11. Young SD, Szekeres G, Coates T. The relationship between online social networking and sexual risk behaviors among men who have sex with men (MSM). PLoS One 2013; 8: e62271.

12. Young SD. Recommended guidelines on using social networking technologies for HIV prevention research. AIDS Behav 2012; 16: 1743-1745.

13. Kalichman SC, Simbayi LC, Jooste S, et al. Development of a brief scale to measure AIDS-related stigma in South Africa. AIDS Behav 2005; 9: 135-143.

14. Young SD, Nussbaum AD, Monin B. Potential moral stigma and reactions to sexually transmitted diseases: evidence for a disjunction fallacy. Pers Soc Psychol Bull 2007; 33: 789-799.

15. Young SD, Szekeres G, Coates T. Sexual risk and HIV prevention behaviors among African-American and Latino MSM social networking users. Int J STD AIDS 2013; 24: 643-649.
16. Brooks RA, Etzel MA, Hinojos E, et al. Preventing HIV among Latino and African American gay and bisexual men in a context of HIV-related stigma, discrimination, and homophobia: perspectives of providers. AIDS Patient Care STDs 2005; 19: 737-744.

17. Malebranche DJ. Black men who have sex with men and the HIV epidemic: Next steps for public health. Am J Public Health 2003; 93: 862-865.

18. Bolding G, Davis M, Hart G, et al. Where young MSM meet their first sexual partner: The role of the Internet. AIDS Behav 2007; 11: 522-526.

19. Fullilove MT, Fullilove RE. Stigma as an obstacle to AIDS action: The case of the African American community. Am Behav Sci 1999; 42: 1117-1129.

20. Marín BV. HIV prevention in the Hispanic community: Sex, culture, and empowerment. J Transcult Nurs 2003; 14: 186-192. 